\title{
Improvement of Weld Fusion Zone Toughness by Fine TiN*
}

\author{
By Shogo KANAZAWA, ${ }^{* *}$ Akira NAKASHIMA, ${ }^{* *}$ Kentaro OKAMOTO** \\ and Ken KANAYA**
}

\section{Synopsis}

A marked improvement in toughness of weld fusion zone in large heat input welding processes such as one-side submerged arc welding, electrogas welding, and electroslag welding has been accomplished through refining of fusion zone microstructure by the aid of fine TiN precipitates.

The following results have been obtained:

(1) Fine TiN precipitates, particularly those smaller than ca. $0.05 \mathrm{k,}$ are effective in preventing austenite grain coarsening. Austenite grain diameter $d_{r}$ at $1400^{\circ} \mathrm{C}$ can be expressed by

$$
d_{\gamma}=K(r / f)
$$

where, $r$ : mean diameter of $\mathrm{TiN}$ remaining undissolved at $1400 \mathrm{C}$

$f$ : volume fraction of the undissolved TiN smaller than $0.05 \mu$ at $1400^{\circ} \mathrm{C}$

$K: \quad 0.12$ (experimental determination).

(2) The fine TiN precipitates are also effective in stimulating ferrite formation. At places where there are fine TiN precipitates congregated in a high concentration prior to cooling transformation, the austenite transforms into a fine structure.

(3) As the result, the diameter of brittle fracture, revealed by the (100) etch pits as to be in the same orientation, becomes smaller. Thus toughness of fusion zone in large heat input welding is greatly improved.

(4) Using these two specific effects of fine TiN precipitates, fusion zone toughness of commercial 40,50 and $60 \mathrm{~kg} / \mathrm{mm}^{2}$ class steels has been improved for a wide range of welding conditions covering small to large heat input.

\section{Introduction}

With the advancement of industrial technology in recent years, steel structures such as ships and crude oil storage tanks have greatly increased in size.

In fabricating these steel structures, large heat input automatic welding processes such as one-side onepass submerged arc welding (SAW), electro-gas welding (EGW), and electro-slag welding (ESW) are frequently employed for improving efficiency. Here the toughness of weldments is of a great practical importance from the viewpoint of structure safety, because the heat affected zone in welded joints, especially those in the neighborhood of fusion lines, often becomes very brittle in these processes.

To secure toughness in the joints, the heat input, or the cooling rate of welded joints, has so far been regarded as the determining factor requiring control. Therefore, steels which can ensure sufficient toughness at fusion zone even in the high heat input welding are being called for.

Two methods of improving toughness in fusion zone are conceivable in alloy design. One is to have the lower bainite structure predominate in the fusion zone by adding such alloying elements as $\mathrm{C}, \mathrm{Mn}, \mathrm{Cr}$ and Mo that have a strong tendency to increase hard- enability. However, if this is applied to such steels as mild steel, HT-50 and HT-60, besides the obvious economical disadvantages, susceptibility to welding cracks under small heat input welding is bound to increase beyond toleration.

The second method consists in stimulating ferrite transformation and causing the fine ferrite-pearlite structure predominate instead of intermediate stage structures. In this method, toughness obtained in fusion zone seems to be quite favourable, as can be inferred from the toughness of fine grain zone produced in weldments through heating to a temperature corresponding to the lower austenite zone.

Through years of research aiming at improving fusion zone toughness in large heat input welding, the authors found that when fine precipitates of titanium nitride (TiN), which is relatively stable at high temperature, are present in 40,50 and $60 \mathrm{~kg} / \mathrm{mm}^{2}$ class high strength steel plates (HT-50 and 60), toughness of fusion zone obtained through large heat input welding is greatly improved. On the basis of this finding, a group of steels suitable for large heat input welding has been successfully developed on a commercial basis, and already used in large amount in ship bulding. Although there are many weldable structural steels containing $\mathrm{Ti}^{1-4)}$ the Vanity steel, for example, there has not been a single case in which TiN is added in steels to make the large heat input welding possible by inhibiting growth of austenite grains based.

\section{II. . Materials and Experimental Procedures}

\section{Steels}

Steels used in the experiments of 3.1 to 3.3 were manufactured in a high frequency induction melting furnace, cast in $100 \mathrm{~kg}$ ingots, forged to $25 \mathrm{~mm}$ thick plate and heat treated (quenched and tempered). The chemical compositions of the steels tested are shown in Table 1. Steels used in 3.4 were the quenched and tempered HT-60 plates (thickness $32 \mathrm{~mm}$ ) that were commercially manufactured in the production line.

\section{Austenite Grain Size}

In Fig. 1, the actual temperature-time curves experienced in various kinds of large heat input welding of $25 \mathrm{~mm}$ thick plates and the simulated temperaturetime curves $\mathrm{A}, \mathrm{B}$ and $\mathrm{C}$ reproduced by a welding HAZ (Heat Affected Zone) simulation apparatus are

* Originally published in Tetsu-to-Hagané, 61 (1975), 2589, in Japanese. English version received October 13, 1975.

** Products Research \& Development Laboratories, Nippon Steel Corp., Fuchinobe, Sagamihara 229. 
Table 1. Chemical composition of steels and precipitates (wt $\%$ )

\begin{tabular}{|c|c|c|c|c|c|c|c|c|c|c|c|c|c|c|c|}
\hline Steel & C & $\mathrm{Si}$ & $\mathrm{Mn}$ & $\mathrm{P}$ & S & $\mathrm{Cu}$ & $\mathrm{Ti}$ & $\mathrm{Zr}$ & Hf & V & $\mathrm{Nb}$ & $\mathrm{Ta}$ & Al sol. & B & Precipitate \\
\hline 1 & 0.14 & 0.30 & 1.30 & 0.015 & 0.009 & 0.01 & - & - & - & - & - & - & 0.001 & - & - \\
\hline 2 & 0.13 & 0.19 & 1.31 & 0.006 & 0.005 & 0.01 & - & - & - & - & - & - & 0.006 & - & - \\
\hline 3 & 0.13 & 0.28 & 1.26 & 0.004 & 0.006 & 0.01 & - & - & - & - & - & 一 & 0.046 & - & $\mathrm{AlN}$ \\
\hline 4 & 0.14 & 0.28 & 1.21 & 0.015 & 0.007 & 0.01 & 0.018 & - & - & - & - & - & 0.015 & 0.0033 & TiN \\
\hline 5 & 0.13 & 0.19 & 1.32 & 0.006 & 0.005 & 0.01 & 0.019 & - & - & - & - & - & 0.007 & - & TiN \\
\hline 6 & 0.14 & 0.29 & 1.31 & 0.015 & 0.009 & 0.01 & 0.021 & - & - & - & - & - & 0.010 & 0.0020 & TiN \\
\hline 7 & 0.13 & 0.24 & 1.12 & 0.005 & 0.005 & 0.01 & - & 0.017 & - & - & - & - & 0.030 & - & $\mathrm{ZrN}$ \\
\hline 8 & 0.13 & 0.32 & 1.42 & 0.012 & 0.011 & 0.08 & - & - & 0.06 & - & - & - & 0.040 & - & ? \\
\hline 9 & 0.13 & 0.32 & 1.36 & 0.013 & 0.006 & 0.01 & - & - & - & 0.045 & - & - & 0.015 & - & $\mathrm{VC}(\mathrm{N})$ \\
\hline 10 & 0.13 & 0.28 & 1.38 & 0.004 & 0.006 & 0.01 & - & - & - & - & 0.022 & - & 0.020 & - & $\mathrm{NbC}(\mathrm{N})$ \\
\hline 11 & 0.15 & 0.50 & 1.20 & 0.004 & 0.008 & 0.01 & - & - & - & - & - & 0.05 & 0.030 & - & $\mathrm{TaC}(\mathrm{N})$ \\
\hline 12 & 0.14 & 0.28 & 1.22 & 0.014 & 0.006 & 0.01 & 0.018 & - & - & - & - & - & 0.015 & 0.0033 & TiN \\
\hline 13 & 0.13 & 0.23 & 1.26 & 0.005 & 0.006 & 0.01 & 0.018 & - & - & - & - & - & 0.004 & 0.0019 & TiN \\
\hline
\end{tabular}

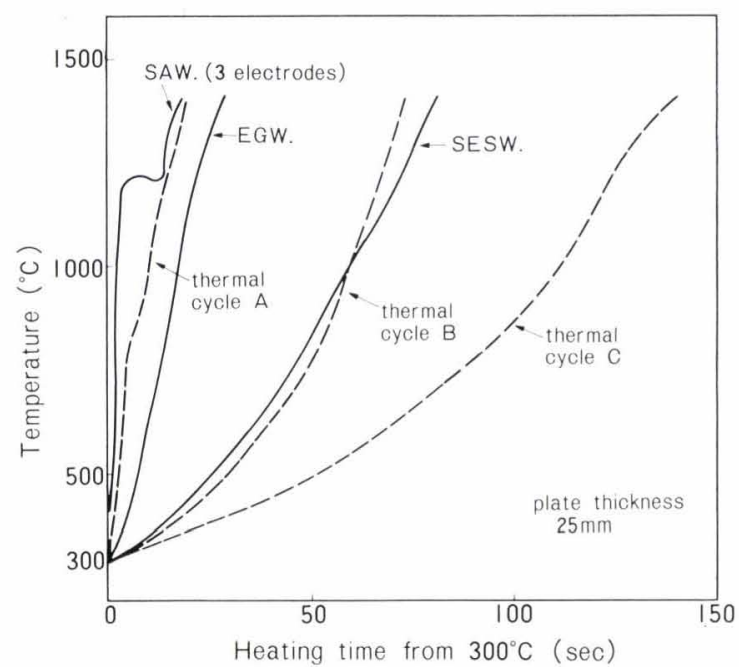

Fig. 1. Heating curves of $25 \mathrm{~mm}$ thick steel plate in various welding processes and synthetic thermal cycles

shown. As soon as the respective maximum temperatures were attained by specimens heat treated according to simulated curve they were quenched in water, etched with picral containing a surface-active agent to reveal austenite grain boundaries, and their mean austenite grain diameters were measured by linear analysis method (numbers of grains over 60).

\section{Transformation Behaviors}

Continuous cooling transformation (CCT) diagrams were made (by Formastor) for the maximum heating temperature of $1200^{\circ}$ or $1400^{\circ} \mathrm{C}$, the latter being the maximum heating temperature of fusion line.

\section{Toughness Test of Synthetic Fusion Zone}

Specimens of $12 \mathrm{~mm} \square \times 70 \mathrm{~mm}$ were taken from quenched and tempered plates and subjected to various thermal cycles to simulate the welding. Charpy specimens (JIS No. 4) were machined from them.

\section{Etch Pits}

In etch pit method, following solutions were used in succession.
A: $\mathrm{H}_{2} \mathrm{O} 100 \mathrm{cc}+\mathrm{H}_{2} \mathrm{O}_{2} 50 \mathrm{cc}+\mathrm{HCl} 5 \mathrm{cc}$

B: $\mathrm{H}_{2} \mathrm{O} 100 \mathrm{cc}+\mathrm{FeCl}_{3} \cdot 6 \mathrm{H}_{2} \mathrm{O}$ saturated aq. sol. $20 \mathrm{cc}+\mathrm{HCl} 5 \mathrm{cc}$

C: $\mathrm{H}_{2} \mathrm{O} 25 \mathrm{cc}+\mathrm{C}_{2} \mathrm{H}_{5} \mathrm{OH} \quad 25 \mathrm{cc}+\mathrm{H}_{2} \mathrm{O}_{2} 25 \mathrm{cc}$ $+\mathrm{HCOOH} 25 \mathrm{cc}$

\section{Precipitates}

Various precipitates were identified by X-ray diffraction of residue extracted by $\mathrm{I}_{2}-\mathrm{CH}_{3} \mathrm{OH}$ sol.

Two methods were employed to investigate the dissolution and precipitation behavior of TiN. One was the observation of carbon extraction replica by electron microscope, in which the specimen was first etched in $\mathrm{HCl}-\mathrm{CH}_{3} \mathrm{OH}(1+1)$ then in picric acid saturated aqueous solution, carbon having been deposited on the specimen in vacuum and the carbon film taken out by $\mathrm{HCl}-\mathrm{CH}_{3} \mathrm{OH}(1+2)$.

The second is the chemical analysis of TiN size, in which the quantities of TiN smaller than $0.05 \mu$ and $0.10 \mu$ were measured respectively. ${ }^{5}$ )

\section{Results and Discussion}

\section{Austenite Grain Growth Inhibition Effect of Fine TiN Precipitates in Fusion Zone}

The effect of various kind of precipitates on the austenite grain growth has been intensively studied. The specimens of quenched and tempered steels \#l to \#13 in Table 1 were heated according to curve A of Fig. 1 quenched from various temperatures during heating, and the relationship between maximum heating temperature and $d_{\gamma}$ was investigated. The results are shown in Fig. 2.

Precipitates in the steels \#1 to \#13 were analyzed by means of X-ray diffraction patterns in the as quenched and tempered condition before submitting to the thermal cycle. It was found that steels containing $\mathrm{Ti}, \mathrm{Zr}, \mathrm{V}, \mathrm{Nb}$ and $\mathrm{Ta}$ had cubic precipitates similar to NaCl, suggesting the presence of TiN, $\mathrm{ZrN}$, $\mathrm{V}_{4} \mathrm{C}_{3}, \mathrm{NbC}$ and $\mathrm{TaC}$, while steels containing $\mathrm{Al}$ had AlN of hexagonal system, but steel \#8 containing Hf yielded diffraction patterns too ambiguous to identify the precipitates.

In comparison to standard steels \#1 and \#2, steels 
\#3 to \#13 containing precipitates were found to possess a finer austenite grain size in all the temperature range; particularly, steels \#4, \#5 and \#12 containing TiN kept the austenite grain size refined even at $1400^{\circ} \mathrm{C}$.

Since the heating speed in large heat input welding varies as shown in Fig. 1, however, austenite grain growth behavior of TiN containing steel \#4 and standard steel \#2 were studied in detail by curves A, $\mathrm{B}$ and $\mathrm{C}$ shown in Fig. 1. Table 2 shows the changes in $d_{\gamma}$ at $1400^{\circ} \mathrm{C}$ in accordance with the different heating curves. It became clear that the effect of heating speed upon $d_{\curlyvee}$ is smaller in TiN containing steel \#4 than in standard steel \#2.

This results suggested the possibility of success in utilizing TiN. To confirm this, the following examinations were done.

\section{TiN Dissolution Phenomena during Welding}

Although TiN is thought to be comparatively stable in a hot steel, some dissolution under welding heat is

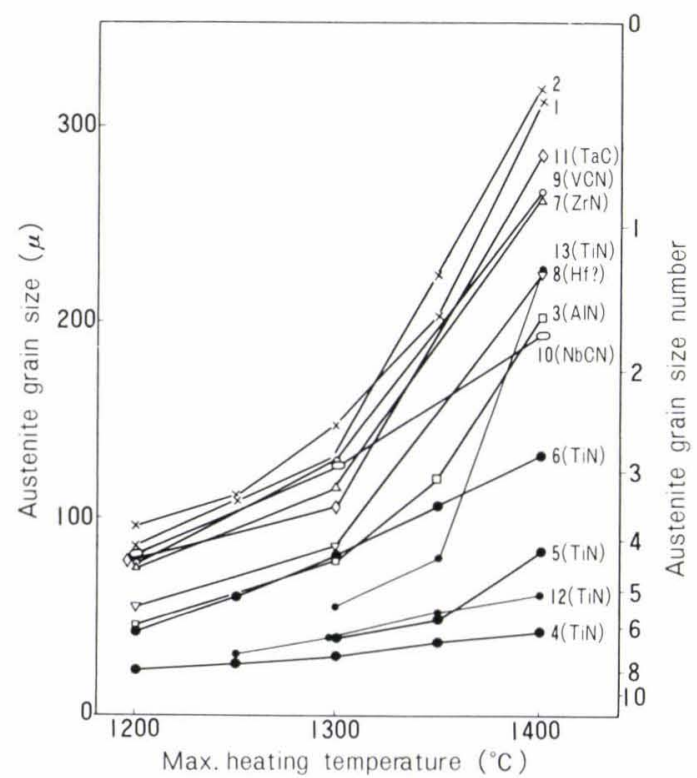

Fig. 2. Relation between maximum heating temperature and austenite grain size

Table 2. Effect of heating rate upon austenite grain size at $1400^{\circ} \mathrm{C}$

\begin{tabular}{|c|c|c|c|}
\hline \multirow{2}{*}{ Steel } & \multicolumn{3}{|c|}{ Thermal cycle in Fig. 1} \\
\hline & A & B & $\mathrm{C}$ \\
\hline \#2 (Ti free) & $319 \mu$ & $403 \mu$ & $533 \mu$ \\
\hline \#4 ( $\mathrm{TiN})$ & $42 \mu$ & $56 \mu$ & $57 \mu$ \\
\hline
\end{tabular}

suspected. Furthermore, because TiN is present in steel in various precipitates sizes ranging from several microns to several hundred angstroms as shown in Photo. 1, its dissolving behavior in such short heating cycle as experienced in wedling is expected to be very complicated.

Figure 3 shows the variation of soluble $\mathrm{Ti}$ and insoluble $\mathrm{Ti}$ of quenched specimen with heating temperatures on steels \#4 and \#6, which are different in austenite grain growth behavior. The quantity of dissolved $\mathrm{Ti}$ was found unchanged up to around $1250^{\circ} \mathrm{C}$, dissolution becoming apparent at $1300^{\circ} \mathrm{C}$, and as such as $0.006 \%$ dissolved at $1400^{\circ} \mathrm{C}$. No significant difference was observed between the two steels in dissolution behavior. This means that the significant difference in austenite grain growth rate between the two steels cannot be explained by TiN dissolution phenomena.

\section{Undissolved TiN and Austenite Grain Diameter $\left(d_{\gamma}\right)$}

On the other hand, it is well established that the inhibition effect of precipitates upon austenite grain growth are dependent on the size and volume fraction of these precipitates. Zener ${ }^{6)}$ and Gladman ${ }^{7)}$ proposed the following relationship:

$$
d_{\gamma}=K(r \mid f)
$$

where, $d_{\gamma}$ : diameter of austenite grains

$r$ : diameter of precipitates

$f$ : volume fraction of precipitates

$K$ : constant.

Specimens of five steels containing TiN were heated

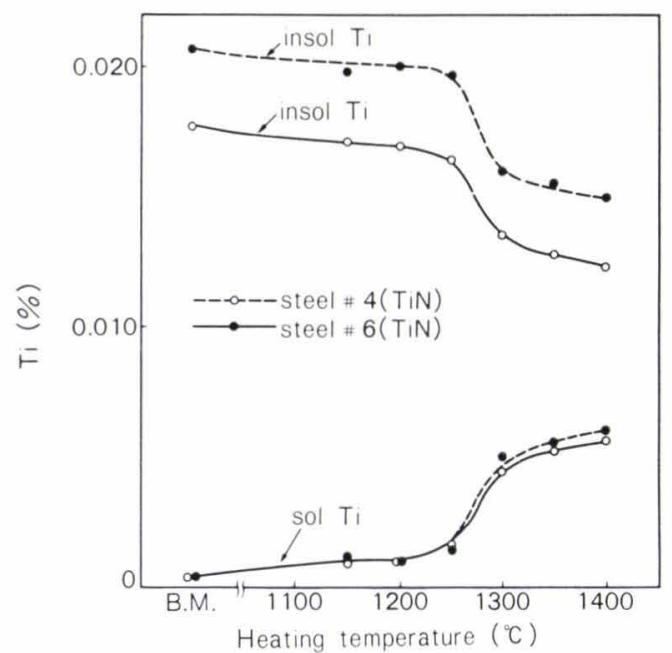

Fig. 3. Dissolution of TiN during heating by synthetic thermal cycle A of Fig. 1
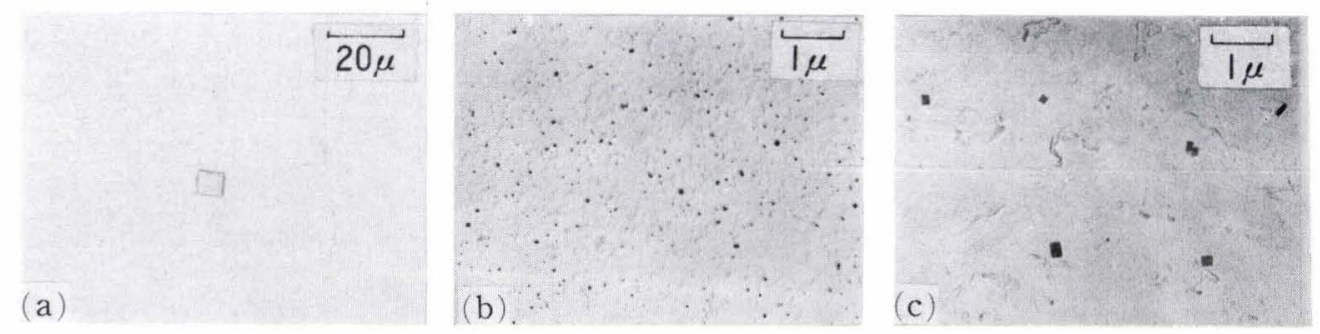

(a) Steel \#6 (TiN) optical micrograph $\quad$ (b) Steel \#4 (TiN) electron micrograph $\quad$ (c) Steel \#6 (TiN) electron micrograph Photo. 1. Optical and electron micrographs of TiN in steels \#4 and \#6 
in mode $\mathrm{A}$ and the values of $d_{\gamma}, r$ and $f$ at $1400^{\circ} \mathrm{C}$ were measured. The results are shown in Fig. 4.

Precipitates diameter $r$ was measured by electron microscope. Particles of TiN larger than $0.05 \mu$ was scarcely observed. This means that the average precipitates diameter $r$ is determined essentially by TiN smaller than $0.05 \mu$.

Volume fraction was calculated from chemical analysis of precipitates smaller than $0.05 \mu, 0.1 \mu$, and of total TiN precipitates and designated as $f_{1}, f_{2}$ and $f_{3}$ respectively. The volume fraction values of TiN precipitates smaller than $0.05 \mu$ (the o-line in Fig. 4) were found to show a significant correlation with the values of $d_{\gamma}$ when $K$ value was 0.12 .

The $K$ value thus obtained was not far from the value of $0.26 \geqq K \geqq 0.05$ proposed by Gladman ${ }^{7)}$ and $K=0.17$ proposed by Kazinczy ${ }^{8}$ (for the austenite grain growth inhibition effect of $\mathrm{NbC}$, and $\mathrm{AlN}$ ).

From all these observations it was inferred that in short heating cycles TiN precipitates were effectively pinning austenite grain boundaries similarly as in the established cases of prolonged heating, so that austenite grain growth was inhibited even at a temperature as high as $1400^{\circ} \mathrm{C}$.

\section{The Size of TiN Precipitates in Steel Plate and Auste- nite Grain Size}

After establishing that $d_{\gamma}$ in fusion zones is dependent on the quantity of fine TiN precipitates remaining undissolved at a given temperature and on their size, possible correlations between $d_{\gamma}$ and the size of TiN precipitates in plate prior to welding were studied.

The TiN quantities existing as precipitates smaller than $0.1 \mu$ and those smaller than $0.05 \mu$ in steel plates before welding were compared with the $d_{\gamma}$ values in these plates heated to $1400^{\circ} \mathrm{C}$, as shown in Fig. 5 . A significant correlation was observed between the quantity of TiN existing as precipitates smaller than $0.1 \mu$ and the size of austenite grain is seen. This is in disagreement with the observation in Fig. 4 as to the size of effective TiN precipitates. This disagreement could be explained by that among TiN precipitates, smaller ones would dissolve in the course of heating and larger ones would become smaller.

\section{Transformation Behavior under the Influence of Fine TiN Precipitates in Fusion Zones}

The transformation behavior of fusion zone of fine TiN containing steel was studied by continuous cooling transformation (CCT) diagrams.

\section{CCT Diagram of Fusion Zone}

A quantity of molten steel was divided into two intermediate tundishes, and a predetermined amount of Ti was added to one of them. The chemical compositions of the two resulting steels are designated in Table 1 as the steels \#2 and \#5. These two steels were subjected to identical hot working and heat treatment processes.

The austenite grain growth behavior of these two steels is shown in Fig. 2. The values of $d_{r}$ at $1400^{\circ} \mathrm{C}$ in the reference steel \#2 and the TiN steel \#5 were 319 and $84 \mu$, respectively.

These specimens were cooled from $1400^{\circ} \mathrm{C}$ at vari-

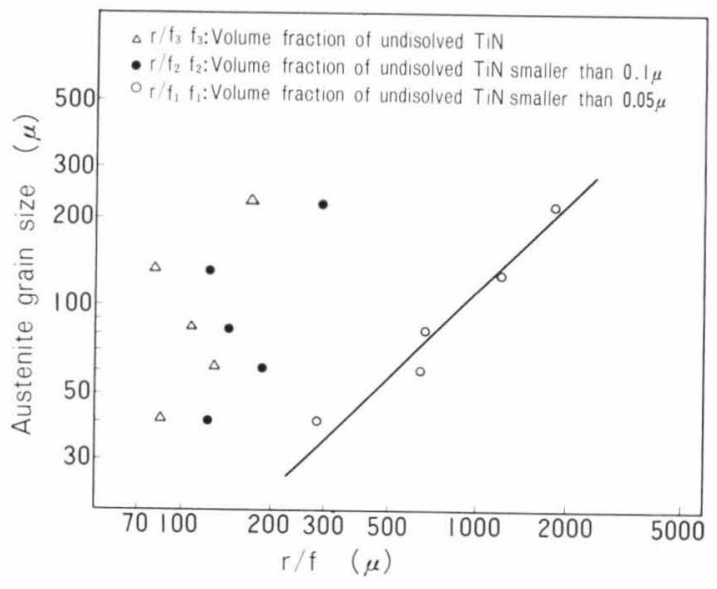

Fig. 4. Correlation between austenite grain size, volume fraction and mean size of undissolved TiN at $1400^{\circ} \mathrm{C}$

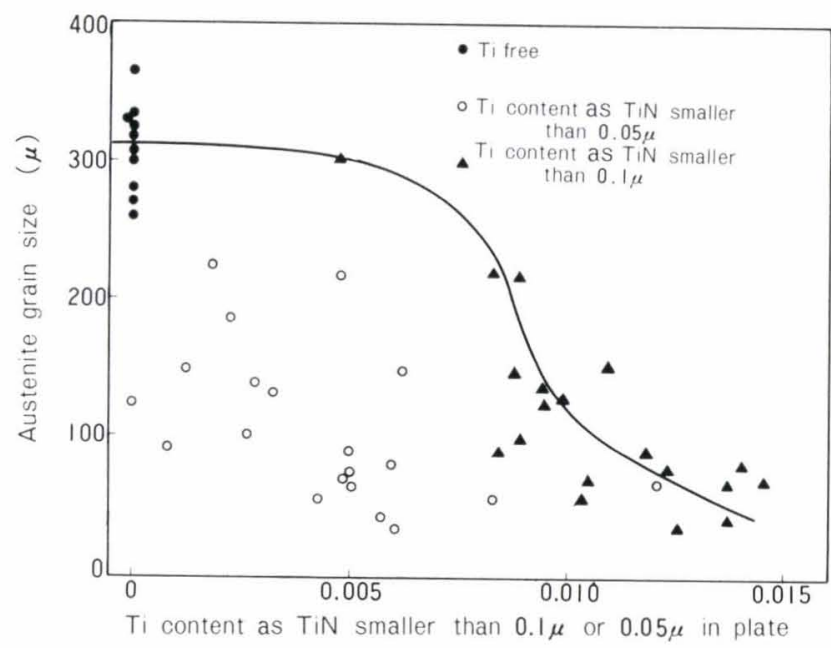

Fig. 5. Relation between austenite grain size at $1400^{\circ} \mathrm{C}$ and $\mathrm{Ti}$ content of TiN smaller than 0.1 or $0.05 \mu$ existing in the plate before welding

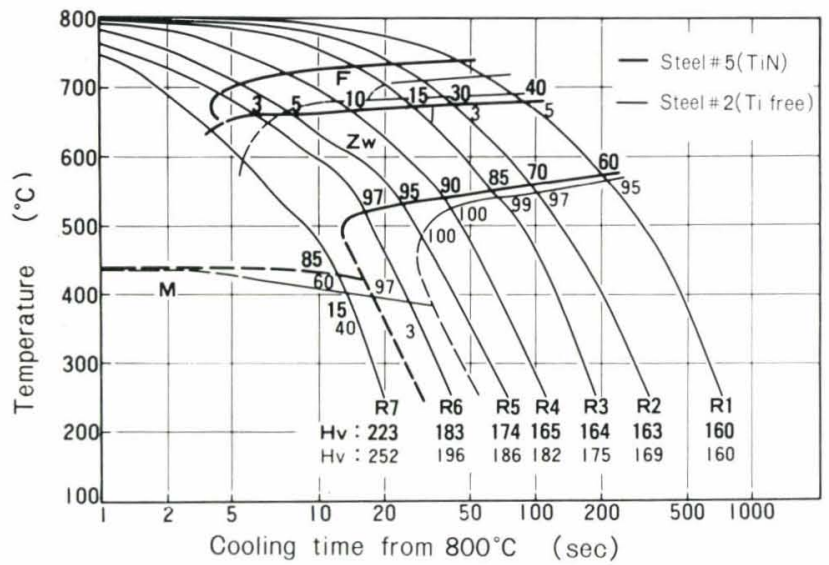

Fig. 6. CCT diagram of steels \#2 and \#5 (max. heating temperature: $1400^{\circ} \mathrm{C}$ )

ous cooling rates and CCT diagrams shown in Fig. 6 were obtained. The steel \#5 containing TiN (thick line) had its ferrite noses protruded more towards the short time side than the reference steel \#2 (fine line). In the cooling range between R1 and R3 where both steels yielded polygonal ferrite structures $\left(F_{P}\right)$, the steel \#5 containing TiN produced by far the more $F_{P}$. The structures at $\mathrm{Rl}$ are shown in Photo. 2. 
This clearly shows that fine TiN can improve the fusion zone microstructure from intermediate stage structure to fine ferrite pearlite.

\section{CCT Diagram with Same Austenite Grain Size}

With a view to examining any possible effects of TiN, besides the obvious effect on the value of $d$, experiments were made with the reference steel \#2 which was heated to $1200^{\circ} \mathrm{C}$ to yield the same $d$. value as the TiN steel \#5 heated to $1400^{\circ} \mathrm{C}$. The CCT diagram in this case is shown in Fig. 7.

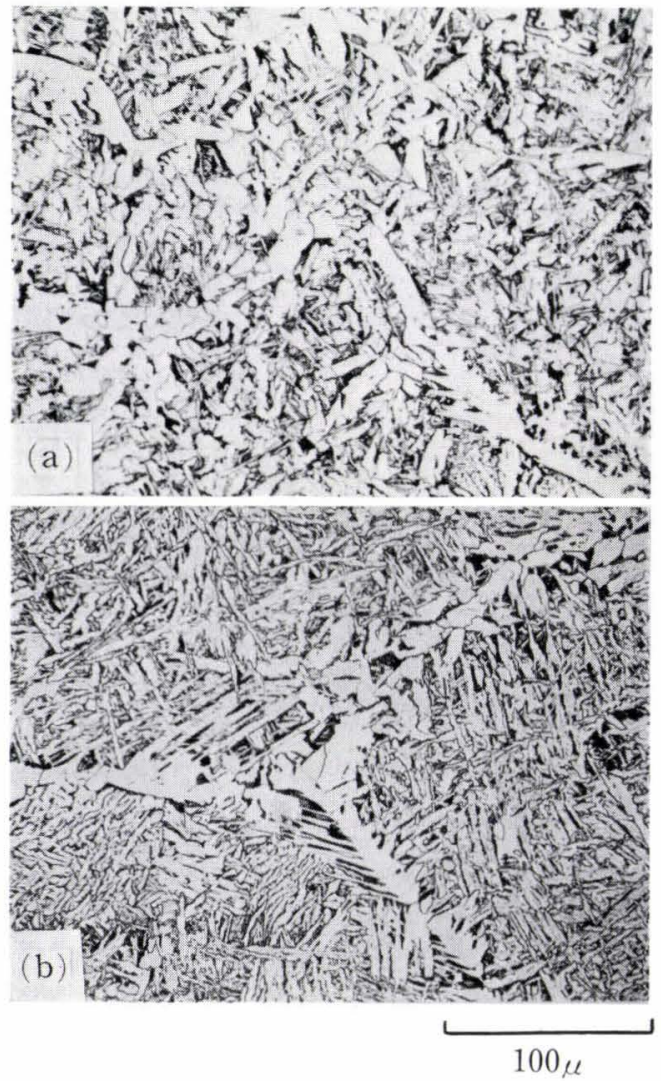

(a) Steel \#5 (TiN) (b) Steel \#2 (Tifree)

Photo. 2. Optical micrographs after cooling at cooling rate of R1 in Fig. 6
Even with the same $d_{r}$ value, the TiN steel \#5 still had the ferrite noses protruded more towards the short time side than the reference steel \#2, as shown in the diagram, with more $F_{P}$ in the former than in the latter in the same cooling condition. The fine TiN is thought to have an effect upon transformation behavior as well as on austenite grain growth.

In the cooling condition R1, a group of specimens of both steels were quenched from a temperature immediately above the beginning of acicular ferrite transformation $\left(F_{A}\right)$, whereas the other group of specimens were quenched from a temperature during the $F_{A}$ transformation. As can be seen in Photos. 3(a) and (b), while the TiN steel \#5 quenched from a temperature just above the $F_{A}$ transformation showed precipitation of primary ferrite nearly all over the austenite grain boundaries, the reference steel \#2 contained untransformed structure to a substantial proportion. As shown in Photos. 3(c) and (d), some of the primary ferrite structures in the TiN steel \#5 quenched during the $F_{A}$ transformation were found to have grown towards grain interior to become $F_{A}$, but the major part was still $F_{P}$ structure, and a notable amount of fine ferrite grains was found to be precip-

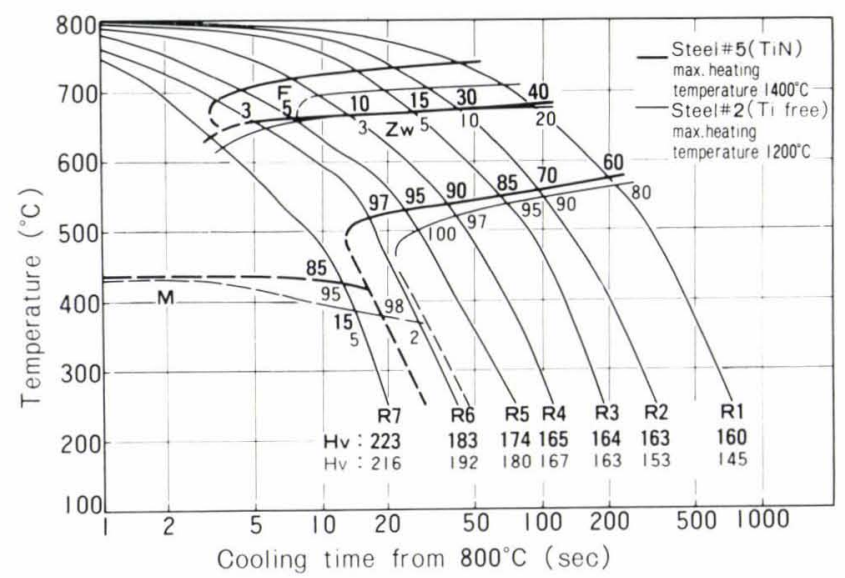

Fig. 7. CCT diagram of steels \#2 and \#5 with same austenite grain size

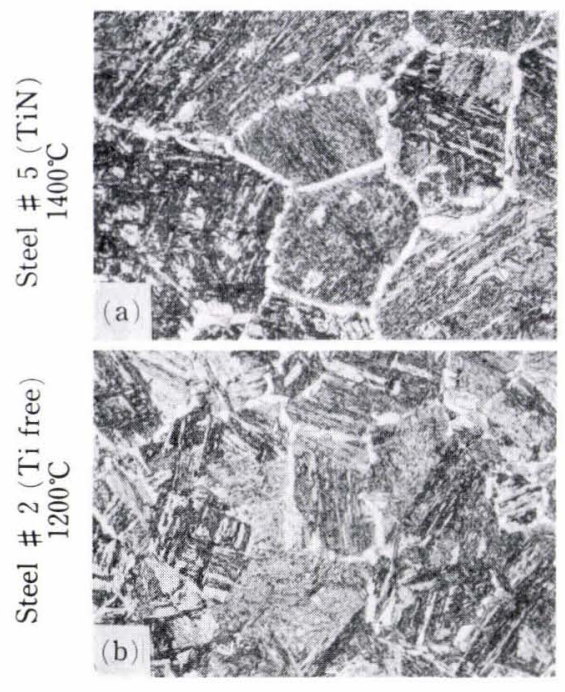

(a) Quenched at $691^{\circ} \mathrm{C}$

(b) Quenched at $681^{\circ} \mathrm{C}$
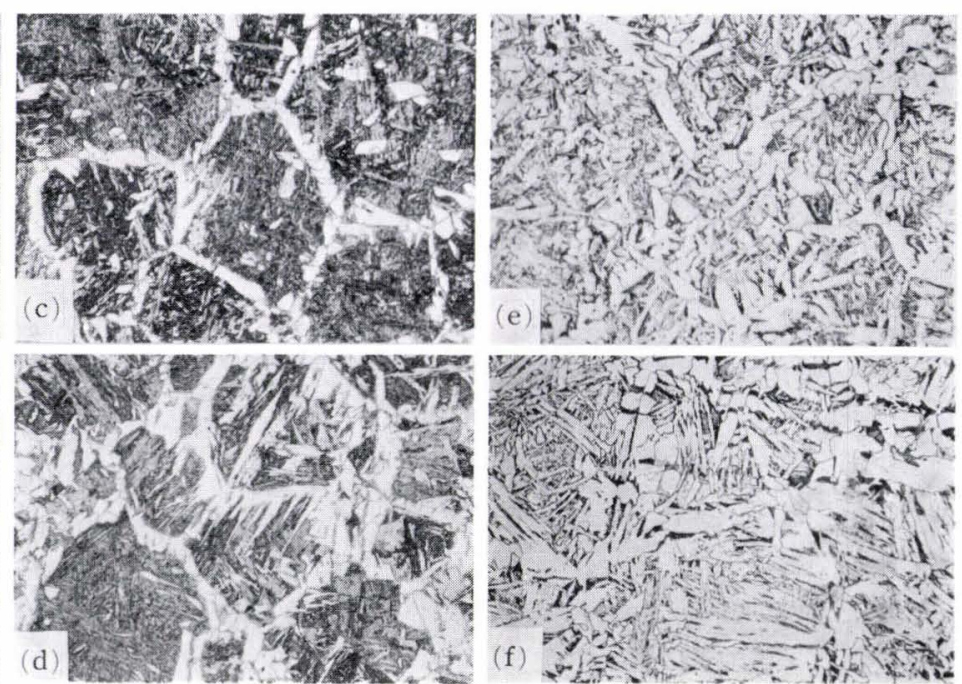

(c) Quenched at $655^{\circ} \mathrm{C}$

(d) Quenched at $638^{\circ} \mathrm{C}$

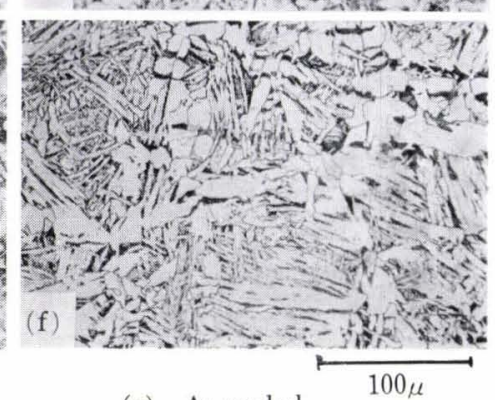

(f) As cooled (e) As cooled

Photo. 3. Comparison of transformation behaviors in cooling at R1 between steels \#5 and \#2 with same austenite grain size 
itated inside the austenite grains.

In the reference steel \#2, on the other hand, no ferrite precipitation was observed within austenite grains, but those ferrite structures which appeared at grain boundaries were found to have grown long towards grain interior. Corresponding to these differences in the transformation behavior between the two steels, there was an obvious difference in their structure at room temperature as seen in Photos. 3(e) and (f): the TiN steel \#5 was found to contain more $F_{P}$ and less $F_{A}$ than the reference steel \#2. Accordingly, the TiN steel \#5 had finer grain structure than the reference steel \#2.

As this difference in transformation behavior was thought to be caused by precipitated TiN particles serving as transformation nuclei, relationship between ferrite structure formation and TiN precipitation was studied with the help of electron microscope by carbon extraction method.

Photograph 4(a), is an electron photomicrograph of the primary ferrite structure transformed at austenite grain boundaries shown in Photo. 3(c). Photograph 4 (b), is an electron photomicrograph of the fine ferrite grains transformed inside the austenite grains shown in Photo. 3(c): By far the more TiN precipitates were observed to have precipitated inside the ferrite structures than in the surrounding martensite structures. Figure 8 shows some results in this regard obtained by the use of iodinemethanol solution.

The TiN precipitation was found to take place entirely during the cooling above the $A_{r 3}$ point, and after transformation initiation, little or no precipitation was observed. From this, ferrite nuclei were inferred to be initiated mostly where there was a dence congregation of TiN precipitates either left undis-

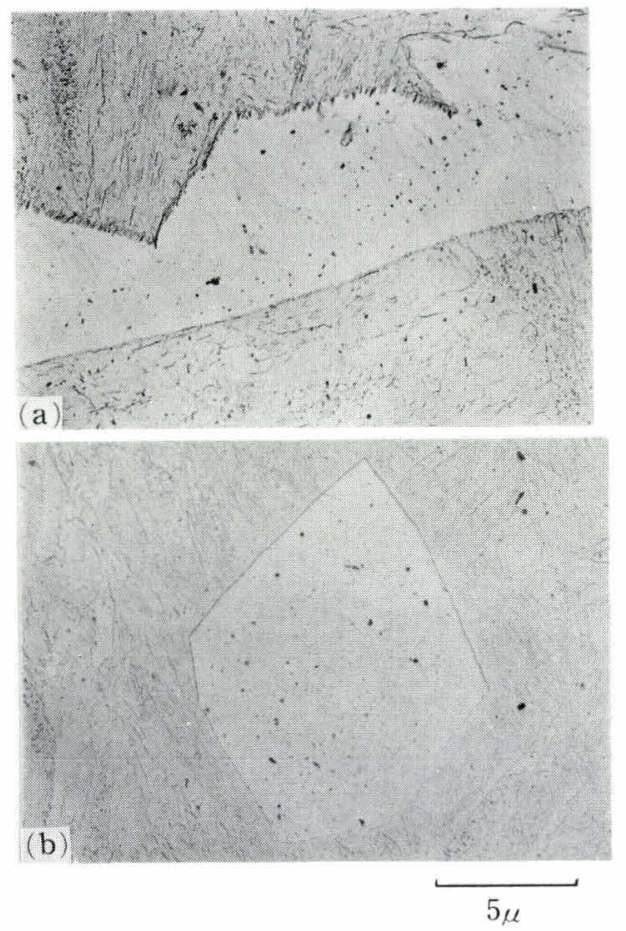

Photo. 4. Fine TiN precipitates in ferrite appearing (a) at the grain boundary and (b) inside of a grain in Photo. 3(c) solved at $1400^{\circ} \mathrm{C}$ or precipitated in austenite structures. Thus TiN was found to have a great influence on steel transformation behavior through its austenite grain growth inhibition effect and ferrite transformation acceleration effect.

\section{Toughness of Weld Fusin Zone of Steel Containing Fine TiN Precipitates}

\section{Correlation between Fusion Zone Toughness and Cool- ing Rate}

When weldments are made through small or medium heat input multi-pass processes, fusion zones are subjected to multiple heating and cooling cycles. Contrary to this, in a one-pass welding process, there is only one cycle, and, because of this, single cycle synthetic thermal cycle tests were expected to have quite close similarlity with actual welding.

The steels \#2, \#4 and \#5 shown in Table 1 were subjected to various synthetic fusion zone thermal cycles, and the measured fracture appearance transition temperatures vTrs were plotted against cooling rates in Fig. 9. The TiN steels \#4 and \#5 were found to have by far the lower $v$ Trs for all the cooling rates than the reference steel \#2.

A specimen of the steel \#2 was heated to $1200^{\circ} \mathrm{C}$ so as to produce austenite grain size comparable with the TiN steel \#5 as heated to $1400^{\circ} \mathrm{C}$, and the mea-

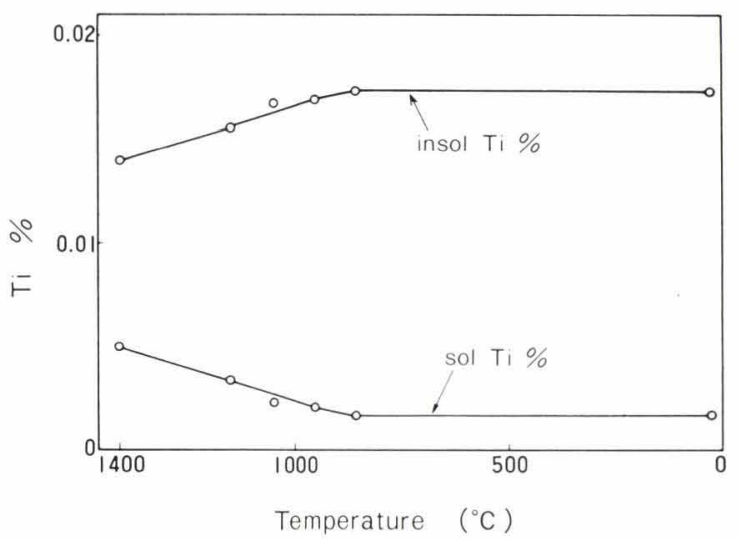

Fig. 8. Reprecipitation phenomena of TiN during cooling in synthetic welding thermal cycle in steel \#5 (cooling rate: $\mathrm{R} 1$ )

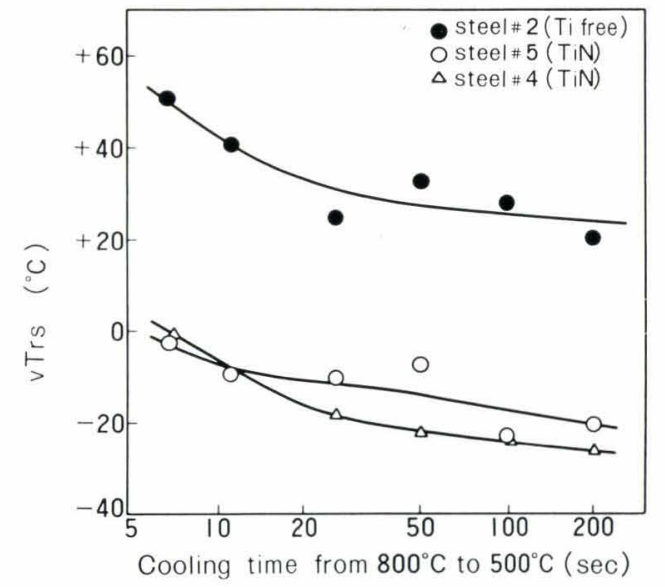

Fig. 9. Impact transition temperatures as a function of cooling time from $800^{\circ}$ to $500^{\circ} \mathrm{C}$ ( $\max$. heating temperature: $1400^{\circ} \mathrm{C}$ ) 
sured $v$ Trs values were plotted against cooling rates in Fig. 10. It was confirmed that even with a comparable $d_{\gamma}$, the fusion zone toughness of the steel \#2 was much lower than that of the TiN steel \#5.

\section{Gorrelation between Fusion Zone Toughness and Maxi- mum Heating Temperature}

Specimens of the steel \#2 and the TiN steel \#5 were heated to a series of maximum heating temperatures in the heating mode A of Fig. 1 and cooled at such a rate that they were cooled from $800^{\circ}$ to $500^{\circ} \mathrm{C}$ in $96 \mathrm{sec}$ (this cooling rate corresponds to that of a fusion zone of $25 \mathrm{~mm}$ thick steel plates as welded in a one-side one-pass SAW at a heat input of 100 $\mathrm{kJ} / \mathrm{cm}$ ), and the measured $v$ Trs temperatures were plotted against the maximum heating temperatures in Fig. 11. The vTrs temperature was found to be the lower the smaller the values of $d_{\gamma}$ and the more ferrite was there.

Again the TiN steel \#5 was found to be the tougher than the reference steel \#2.

3. Correlation between Toughness and Unit Grack Length Normally, the toughness of metal is determined not only by alloy composition and microstructures but also by unit crack length in a complicated combination.

In order to obtain a unified interpretation applicable to Figs. 9 to 11, specimens were impact tested in a Charpy testing machine at $-196^{\circ} \mathrm{C}$, and the fracture surfaces were examined by a scanning elec-

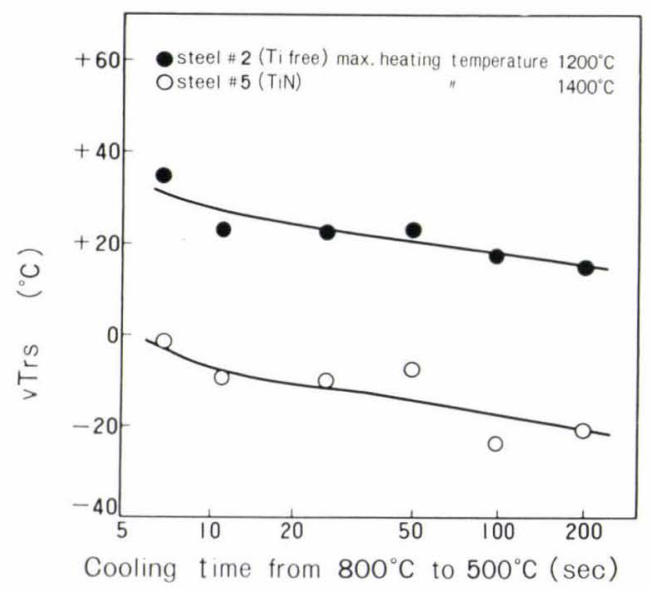

Fig. 10. Impact transition temperatures as a function of cooling time from $800^{\circ}$ to $500^{\circ} \mathrm{C}$ in steels \#2 and \#5 with same austenite grain size tron microscope. Representative photomicrographs are shown in Photo. 5. If the areas surrounded by heavy tear lines were to represent unit crack lengths, the steel \#5 heated to $1400^{\circ} \mathrm{C}$, the steel \#2 heated to $1200^{\circ} \mathrm{C}$ and the steel \#2 heated to $1400^{\circ} \mathrm{C}$ were found to have increasing unit crack lengths and also increasing $v$ Trs temperatures in this order.

Thus, a possibility of evaluating toughness by Charpy test unit crack lengths was confirmed. However, it had been reported that not all the heavy tear lines have equal bearing on toughness, ${ }^{6)}$ and also, unit crack lengths are hard to measure accurately in photomicrographs such as shown in Photo. 5.

To obviate this difficulty, etch pits method were used to reveal an area that shares (100) plane in a small angular deviation with the assumption that this area is the unit facet of brittle fracture, and this area was compared with fracture appearance and subcracks in Charpy test as shown in Photo. 6. It was found that Charpy main cracks taking the form of fracture surfaces and sub-cracks had high degree of correlation with unit area that were identified by etch pits.

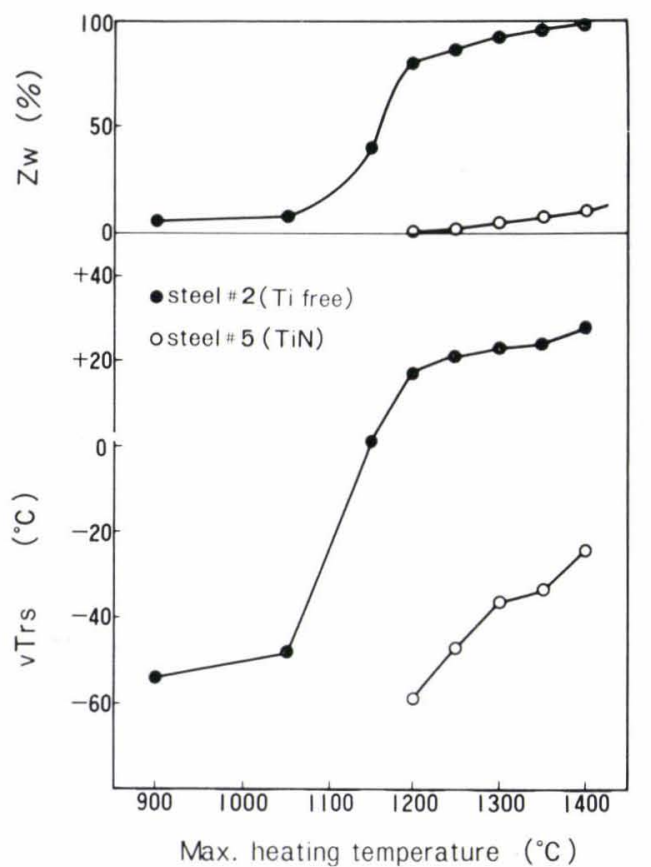

Fig. 11. Change of microstructure and $v$ Trs with max. heating temperature in steels \#2 and \#5

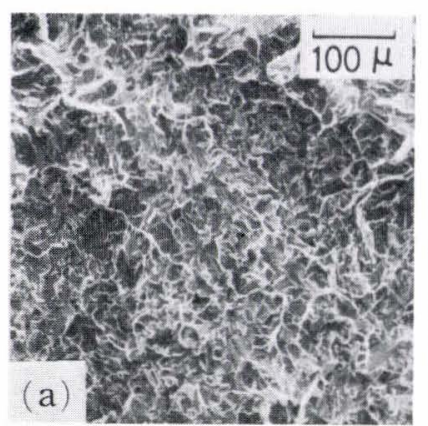

(a) Steel \#5: $d_{\gamma}: 84 \mu$ Max. heating temperature: $\begin{array}{ll}\text { (a) } 1400^{\circ} \mathrm{C} & \text { (b) } 1200^{\circ} \mathrm{C}\end{array}$

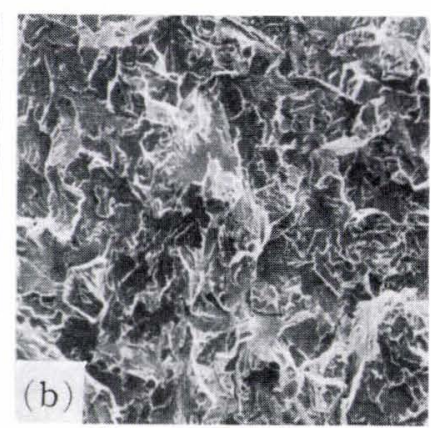

(b) Steel \#2: $d_{\gamma}: 85 \mu$

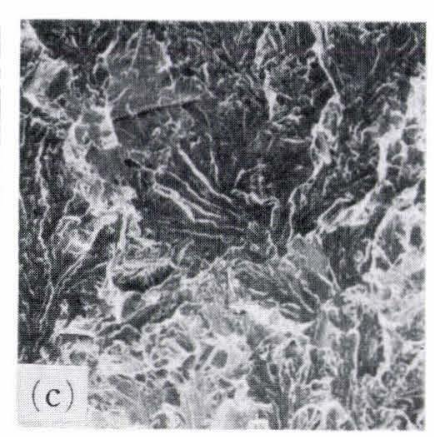

(c) Steel \#2: $d_{\gamma}: 319 / 1$

Photo. 5. An example of fracture appearance (cooling time from $800^{\circ}$ to $500^{\circ} \mathrm{C}$ is $96 \mathrm{sec}$.) 
In Fig. 12, the toughness test data of Figs. 9 to 11 are plotted with respect to the mean diameters $d_{c}$ of the area that were identified by etch pits. It will be seen that a very high degree of correlation exists between $v$ Trs and $d_{c}$. The portion having small inclination represents the structures mainly consisting of $F_{A}$, and the steep portion represents the structures mainly consisting of $F_{P}$.

It is interesting to note in this diagram that the correlation between fusion zone toughness and unit crack length are identical in appearance between the TiN steel \#5 and the reference steel \#2 without Ti. Therefore, it is concluded that any difference in unit crack length is produced by the austenite grain growth inhibition effect and the ferrite transformation acceleration effect of TiN.

\section{Commercial Weldable Steel Adapted to Large Heat Input Welding Processes by Fine TiN Precipitates}

Already a substantial quantity of 40,50 and 60 $\mathrm{kg} / \mathrm{mm}^{2}$ class weldable steels, made adaptable to large heat input welding processes by providing fine TiN precipitates in them, has been commercially produced and used.

The details of the method of distributing fine TiN precipitates in steel, the various properties of these steels, and the welding filler rods for them will be given in a later report. Here, a commercially produced $60 \mathrm{~kg} / \mathrm{mm}^{2}$ TiN steel (HT-60S) shall be briefly described as an example.

(1) In Table 3, the mechanical properties of 32 $\mathrm{mm}$ thick HT-60S and a conventional $60 \mathrm{~kg} / \mathrm{mm}^{2}$ steel (HT-60) after heat treatment are compared. As far as the chemical composition is concerned, the only difference between HT-60S and HT-60 is that Ti is present in the former.

(2) In Fig. 13, the strength (long gage) and toughness (as expressed by $v$ Trs) of the welded joints made by various welding processes (manual welding, SAW, EGW and SESW) are plotted against the time of cooling the fusion zone from $800^{\circ}$ to $500^{\circ} \mathrm{C}$. Although all the specimens appear to lose strength as the cooling rate becomes small, in all the heat input range tested they show a tensile strength above $62 \mathrm{~kg} / \mathrm{mm}^{2}$ conforming to the requirements for $60 \mathrm{~kg} / \mathrm{mm}^{2}$ grade steels.

(3) With respect to the fusion zone toughness, the HT-60S was higher than the reference steel for all the tested heat input range. The joints of HT-60S made through a one-side, one-pass SAW, EGW, SESW at high heat input showed fusion zone toughness values comparable with those of the joints of the reference steel made through welding processes at low heat input.

It might be noted that the correlation between fusion zone toughness and cooling rate in Fig. 13 is different from that in Fig. 9 (or Fig. 10). This difference is due to a difference in the structure in the high cooling rate ranges in the two diagrams: Figures 9 and 10 represent data of the fusion zone heated by the synthetic fusion zone induction heating apparatus in single heating cycle, so that the toughness values in the high cooling rate were those of martensite or bainite. In Fig. 13, on the other hand, specimens

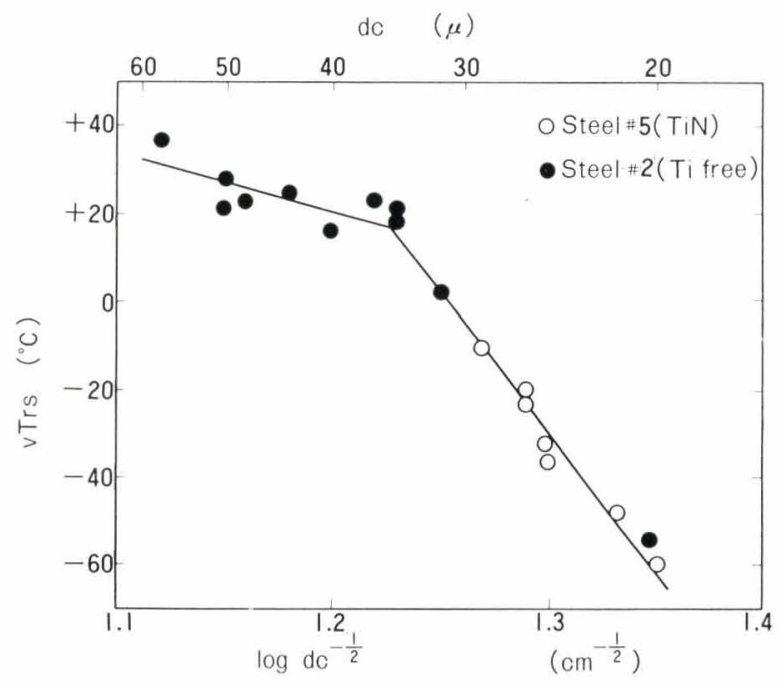

Fig. 12. Relation between vTrs of synthetic heat affected zone and effective grain size $\left(d_{c}\right)$
Photo. 6 .

Relation between heavy tear lines in fracture surface (a) or subcrack (b) in Charpy impact specimen and effective grain size determined by etch pit method
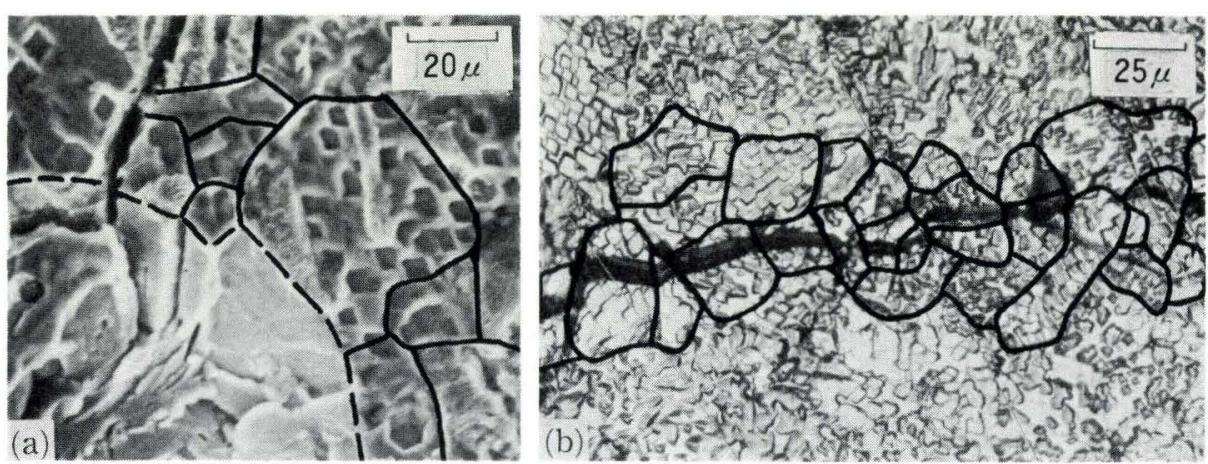

Table 3. Mechanical properties of quenched and tempered $60 \mathrm{~kg} / \mathrm{mm}^{2}$ high strength steels (32 mm thick)

\begin{tabular}{l|cccccccc}
\multicolumn{1}{c}{ Steel } & $\begin{array}{c}\text { T. S } \\
\left(\mathrm{kg} / \mathrm{mm}^{2}\right)\end{array}$ & $\begin{array}{c}\text { Y. P } \\
\left(\mathrm{kg} / \mathrm{mm}^{2}\right)\end{array}$ & $\begin{array}{c}\text { El. } \\
(\%)\end{array}$ & $\begin{array}{c}\text { R. A } \\
(\%)\end{array}$ & Bend & $\begin{array}{c}v E-20 \\
(\mathrm{~kg}-\mathrm{m})\end{array}$ & $\begin{array}{c}v E-40 \\
(\mathrm{~kg}-\mathrm{m})\end{array}$ & $\begin{array}{c}v \text { Trs } \\
\left({ }^{\circ} \mathrm{C}\right)\end{array}$ \\
\hline HT-60S & 64.2 & 52.3 & 28 & 68 & Good & 21.8 & 17.5 & -71 \\
HT-60 & 64.8 & 51.7 & 28 & 69 & $\ldots$ & 14.6 & 10.0
\end{tabular}


cooled faster than in $80 \mathrm{sec}$ represent multi-pass welding processes so that the fusion zone toughness values are those of tempered martensite or tempered bainite as produced by repeated welding passes. Obviously the latter joints should be tougher than the former joints.

In Fig. 14, the toughness values of welded joints made through a one-side, one-pass SAW process (206 $\mathrm{kJ} / \mathrm{cm}$ heat input) in the two steels measured at various locations through $2 \mathrm{~mm} \mathrm{~V}$-notch Charpy impact tests at $-10^{\circ} \mathrm{C}$ are shown in terms of absorbed energy $(v E-10)$. It will be seen that the HT-60S gives higher energy values at all locations than the reference steel, the values all amply satisfying the steel grade approval standard of $v E-10 \geqq 4.8 \mathrm{~kg}-\mathrm{m}$

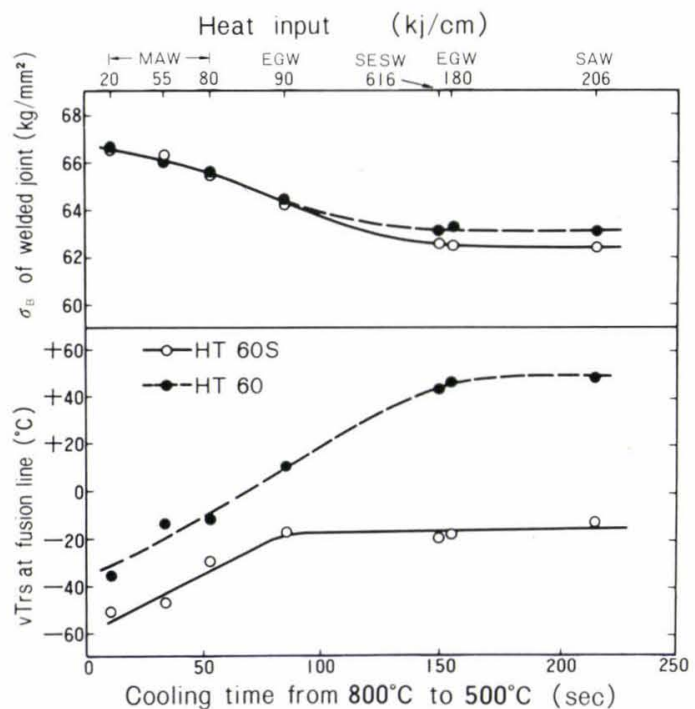

Fig. 13. Relation between strength and toughness of welded joint and cooling rate at fusion zone

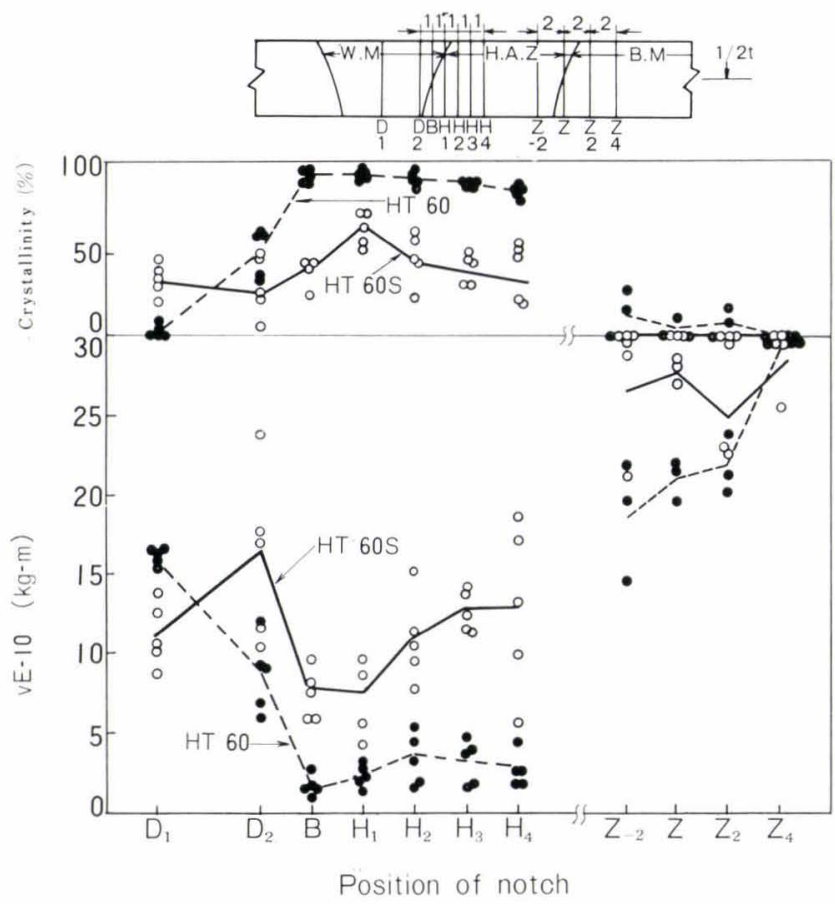

Fig. 14. $2 \mathrm{~mm} \mathrm{V-notch} \mathrm{Charpy} \mathrm{test} \mathrm{results} \mathrm{at} \mathrm{various} \mathrm{notch}$ positions of one-side, one-pass submerged arc welded joint $(206 \mathrm{~kJ} / \mathrm{cm})$ in $60 \mathrm{~kg} / \mathrm{mm}^{2}$ high strength steels with TiN (HT-60S) and without TiN (HT$60)$. specified for HW-50 steel plates $\left(\sigma_{y} \geqq 50 \mathrm{~kg} / \mathrm{mm}^{2}\right)$ by The Japan Welding Engineering Society.

(4) Besides the foregoing comparison in terms of Charpy impact test results, brittle fracture tests with large specimens were also made. For brittle fracture initiation tests, the deep notch test, the Wells test and the wide plate test with surface notch and angular distortion, while for brittle fracture propagation arresting tests, the modified ESSO test (as adopted by the Shipbuilding Research Association of Japan as shown in Fig. 15) were performed.

In Fig. 16, the results of the brittle fracture propagation arresting tests performed on one-side onepass SAW welding fusion zone are given. As in the Charpy tests, the HT-60S showed by far the higher fracture toughness values $\left(K_{c}\right)$ than those of the reference steel. In all those brittle fracture initiation tests, the HT-60S was higher in the fracture toughness values than the reference steel.

(5) Photograph 7 represents optical photomicrographs of structures in the neighborhood of the fusion zone made in one-side, one-pass SAW process. The
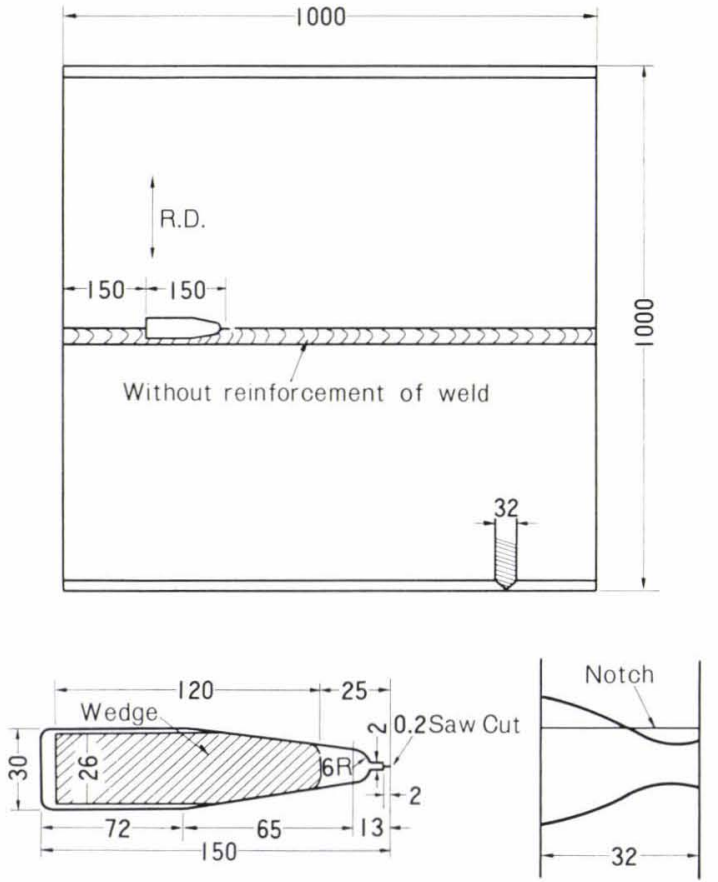

Fig. 15. Modified ESSO specimen

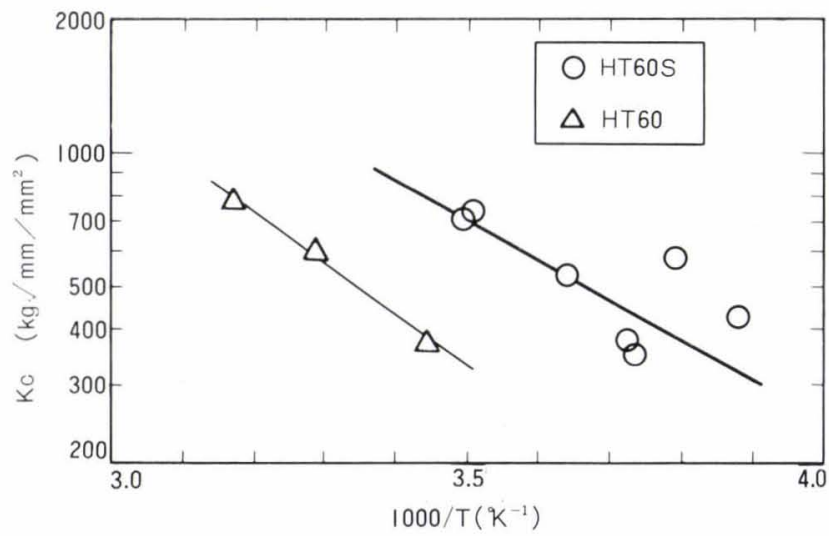

Fig. 16. Temperature dependence of $K_{r}$ value of one-side, one-pass SAW welding fusion zone (modified ESSO test) 
Photo. 7.

Optical micrograph of fusion zone of submerged arc welded joint

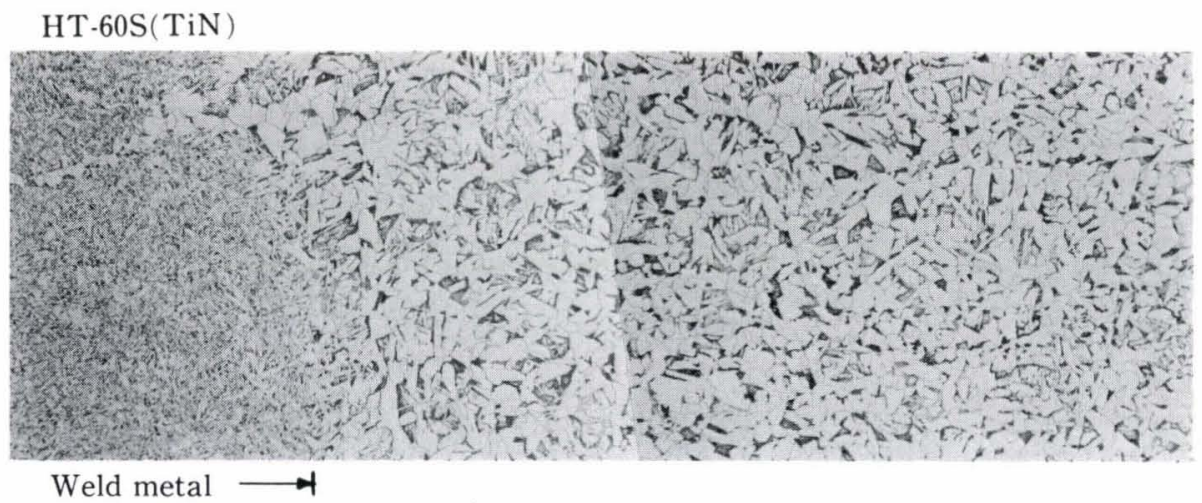

Weld metal $\longrightarrow$

HT-60(Ti free)

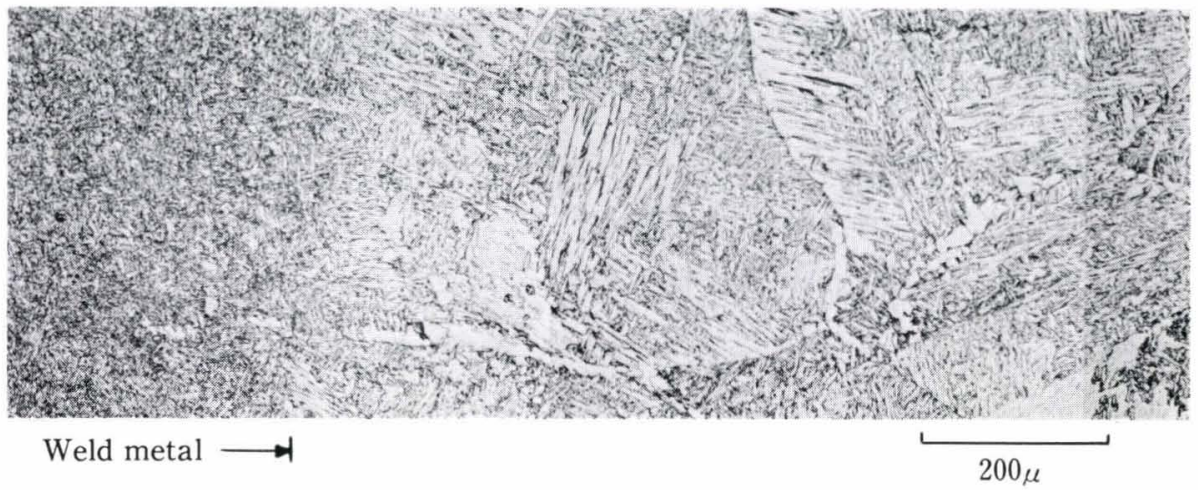

structures in the HT-60S fusion zone consists mostly of fine ferrite-pearlite, while those in the reference steel were intermediate stage structures. The structural difference between the two steels was so great that no optical microscope was required to discriminate the two, as the two macro-etched welded joint sections were substantially different to the naked eye, the fusion zone of the reference steel containing coarse grain regions, whereas that of the HT-60S steel containing no such regions.

\section{Conclusion}

(1) A marked improvement of toughness in the fusion zone of weldment made by large heat input one-pass welding processes such as one-side, one-pass submerged arc welding, electrogas welding and consumable nozzle electroslag welding has been accomplished through a refinement of fusion zone microstructure effected under the influence of fine TiN precipitates, where fine ferrite-pearlite structures were produced in place of the ordinary coarse intermediate stage structures.

(2) The fine TiN precipitates were found to be effective in preventing austenite grain coarsening. Austenite grain diameter $d_{r}$ at $1400^{\circ} \mathrm{C}$ was found to accord with $d_{\gamma}=K(r / f)$. The more the TiN precipitates of sizes smaller than $0.05 \mu$ remaining undissolved at $1400^{\circ} \mathrm{C}$, the more refined became the austenite grains.

(3) Besides the austenite grain growth inhibition effect, the fine TiN precipitates found to stimulate ferrite transformation; namely where fine TiN precipitates were present in a high concentration prior to cooling transformation, polygonal ferrite nuclei were found to be produced, when the transformation structures were further refined, and the unit facet diameter of brittle fracture, which almost coincided with that identified by (100) plane etching pits, became smaller.

(4) Through the utilization of these two effects of fine TiN precipitates, the fusion zone toughness of commercial 40, 50 and $60 \mathrm{~kg} / \mathrm{mm}^{2}$ class steels has been improved for a widely different welding modes covering small to large heat input range.

\section{Acknowledgements}

The authors wish to thank their senior members and related research group members at the Products Research \& Development Laboratories of Nippon Steel Corp., who had unsparingly extended to them their cooperation and guidance, and members of Hirohata Works, Kimitsu Works, and the Head Office of Nippon Steel Corp., who gave valuable contributions in the matter of steel production technology.

\section{REFERENCES}

1) U. S. Navy: Vanity Steel in Spec. 4835.

2) H. Kihara and H. Suzuki: Welding of High Strength Steel, Welding Book Series, The Japan Welding Engineering Society, Tokyo, (1958), 36.

3) Yawata Iron Works, NSC: " High Strength Steel Design Manual ", Riko Tosyo Co., Tokyo, (1964), 193.

4) Y. Onoe, S. Sekino, Y. Shiomi and M. Sato: Tetsu-toHagané, 60 (1974), 1144.

5) K. Kawamura, S. Watanabe, T. Uchida and S. Suzuki: Tetsu-to-Hagané, 60 (1974), S656.

6) C. Zener: Trans. AIME, 175 (1948), 45.

7) T. Gladman: Proc. Roy. Soc., A. 294 (1966), 298.

8) N. E. Hannerz and F. De Kazinczy: JISI, 208 (1970) 475.

9) Iron and Steel Institute of Japan and Japan Institute of Metals: Toughness of Steel, Climax Molybdenum Co., (1971), 47. 